\title{
Detection of Borrelia burgdorferi in cerebrospinal fluid by the polymerase chain reaction
}

\author{
W. H. KRÜGER* and M. PULZ \\ Institute of Medical Microbiology and Immunology, University Hospital Eppendorf, Martinistrasse 52, 2000 Hamburg \\ 20, Germany
}

\begin{abstract}
Summary. The polymerase chain reaction (PCR) was used to amplify specific DNA sequences from different clinical isolates of Borrelia burgdorferi and from cerebrospinal fluid (CSF) of two patients with Lyme disease of the central nervous system. The amplification products were separated by polyacrylamide gel electrophoresis and visualised by ethidium bromide staining. The definitive identification of amplified DNA as a part of the B. burgdorferi flagellin gene was achieved by hybridisation to a 40-base oligonucleotide probe complementary to a part of the spirochaetal gene but not to the primers. Attempts to cultivate borreliae from either patient were unsuccessful and one patient had no serological marker in serum or CSF to indicate borreliosis. Clinical symptoms of both patients regressed with antibiotic therapy. The PCR system is a powerful and rapid technique to amplify flagellin gene sequences from CSF of patients with neuroborreliosis. Only one-tenth of the time needed for cultivation was required from CSF sampling to diagnosis. Gene amplification might, for the first time, allow effective monitoring of therapy for patients with Lyme disease of the central nervous system.
\end{abstract}

\section{Introduction}

Lyme borreliosis, caused by the spirochaete Borrelia burgdorferi is the most frequent tick-borne disease in Europe and the USA. ${ }^{1-4}$ Meningitis, cranial neuritis and painful radiculoneuritis have been reported to be common neurological disorders in this infection. ${ }^{5-8}$

Diagnosis of borreliosis of the central nervous system relies mainly on clinical and serological features. Antibodies against B. burgdorferi in blood and cerebrospinal fluid (CSF) are demonstrable by indirect immunofluorescence, ELISA and Western blotting. ${ }^{9-11}$ Complete confidence in these tests is probably misplaced; around $20-50 \%$ of cases have no measurable antibody response during the first few weeks $^{12-15}$ and cases of seronegative neuroborreliosis have been described in which $B$. burgdorferi was isolated from CSF. ${ }^{4,15-17}$ However, cultivation of B. burgdorferi from CSF requires 4-6 weeks and is often unsuccessful. ${ }^{18-20}$ Thus, techniques for the rapid detection of spirochaetes in clinical samples are needed. ${ }^{21,22}$

The polymerase chain reaction (PCR) is a technique for detecting nucleic acids based on a nearly exponential multiplication of a defined DNA template. ${ }^{23}$ In this report, we describe two oligonucleotides designed

Received 18 Sep. 1990; revised version accepted 26 Nov. 1990 *Present address, to which correspondence should be sent: Bone Marrow Transplantation Unit, Department of Haematology/ Oncology, University Hospital Eppendorf, Martinistrasse 52, 2000 Hamburg 20, Germany. to amplify a segment of the B. burgdorferi flagellin gene. A further oligonucleotide, with no homology to the PCR primers, was used for the specific detection of the amplified products by hybridisation. We used this method to detect Lyme disease spirochaete DNA in CSF from two patients with neuroborreliosis.

\section{Materials and methods}

\section{Bacterial strains}

B. burgdorferi reference strains B31 (ATCC 35210) and IRS (ATCC 35211) were used as positive controls. Clinical isolates of $B$. burgdorferi from CSF (strains 50 and 387) and from tissue biopsy samples of erythema chronicum migrans (strains N34 and PKO) were kindly provided by R. Ackermann, Cologne (N34), V. Sticht-Groh, Würzburg $(50,387)$ and $\mathrm{B}$. Wilske, Munich (PKO). All borreliae were cultured in modified Kelly medium and passaged twice weekly. ${ }^{24}$ Numbers of spirochaetes were determined by dark field microscopy with a Petroff-Hauser counting chamber.

\section{Patients}

The first patient was a 50-year-old man. In November 1989 he had a febrile illness. In December he developed neurological symptoms including meningitis and cranial nerve (VI and VII) palsies. He was admitted to our hospital with the additional signs of an early psychosyndrome. He remembered no tick 
bite. The second patient was a 10-year-old boy who was admitted to hospital because of a left sided facial palsy. The parents reported a tick bite followed by an apparent erythema migrans sometime before the onset of the neurological disorder.

\section{Laboratory investigations and clinical specimens}

Examination of CSF from the first patient showed a lymphocytosis (4200 cells $/ \mu \mathrm{l})$ and elevated total protein, IgG and glucose concentrations. Oligoclonal IgG was detected in CSF by iso-electric focusing. The CSF albumin : serum albumin ratio revealed a bloodbrain barrier dysfunction. B. burgdorferi-specific Western blots showed a negative result with serum but revealed a specific IgG response in CSF. Cultivation of $B$. burgdorferi from CSF samples was attempted in duplicate before antibiotic therapy was started but cultures remained negative after incubation for 6 weeks. During therapy with cefotaxime $(2 \mathrm{~g}$, three times daily for 14 days) cranial neuritis disappeared and lymphocytosis decreased.

Examination of CSF from the second patient also revealed a lymphocytosis. Borrelia-specific antibodies were not detected in serum or CSF and spirochaetes were not cultivated from CSF. The diagnosis was based primarily on clinical features. Lymphocytosis and paresis regressed with antibiotic therapy (penicillin-G, 4.5 million units, three times daily for 14 days).

Neurosyphilis involving the CNS was excluded in both patients by serological tests. Meningitis, caused by classical bacterial agents, and tuberculosis were excluded by standard examinations. Cell culture and serological screening for neurotropic viruses gave negative results.

CSF samples were used for the PCR.

\section{Negative controls}

As negative controls for PCR, DNA extracted from the human lymphocyte line H9-(a gift from R. Gallo, Bethesda, MD, USA) and CSF samples from neurosurgical patients with no evidence of Lyme borreliosis were used. PCR assays were also performed with suspensions $\left(10^{5}\right.$ bacteria $\left./ \mathrm{ml}\right)$ of agents of typical bacterial meningitis-Escherichia coli, Neisseria meningitidis, Haemophilus influenzae, Streptococcus pneumoniae, Staphylococcus aureus and Mycobacterium tuberculosis.

\section{Synthetic oligonucleotides}

The oligonucleotides were synthesised on an Applied Biosystems synthesiser with the automated phosphoramidite coupling method. The primer pair for the PCR procedure, termed WK1 and WK2, and the hybridisation oligonucleotide WK 3 were deduced from the gene sequence for the flagellin of $B$. burgdorferi published by Gassmann et al. ${ }^{25}$ Nucleotide sequences are shown in fig. 1. The oligonucleotide used in the hybridisation assay was radiolabelled with $\left[\gamma^{-32} \mathrm{P}\right] \mathrm{ATP} .{ }^{26}$
WK 1: AAGGAATTGGCAGTTCAATC (271-290)

WK2: GTTCTACTTCGATAACGACT (541-560)

\section{WK3: AATGCACATGTTATCAAACAAATCTGCTTC}

(396-425)

Fig. 1. Oligonucleotides used for amplification of and hybridisation with $B$. burgdorferi flagellin gene sequences. ${ }^{13}$ WK 2 is shown in the $3^{\prime}-5^{\prime}$ orientation and complementary to the published strand.

\section{PCR}

Cultures of B. burgdorferi containing $c .10^{8}$ organisms $/ \mathrm{ml}$ were diluted up to $10^{5}$-fold in distilled water. The concentration of $\mathrm{H} 9-$ DNA was adjusted to $0 \cdot 1 \mu \mathrm{g} / \mu \mathrm{l}$. CSF samples, c. $3 \mathrm{ml}$, were centrifuged at $1000 \mathrm{~g}$ for $10 \mathrm{~min}$, then the pellet was resuspended in a few drops of supernate. All samples, except for the H9 - DNA, were boiled for $10 \mathrm{~min}$ in a water bath. Amplifications were performed with $10 \mu \mathrm{l}$ of each sample added to a final volume of $100 \mu \mathrm{l}$ with $10 \mu \mathrm{l}$ of 10-fold concentrated Thermus aquaticus polymerase reaction buffer, dNTP mix, distilled water and $2 \mathrm{U}$ of T. aquaticus polymerase (Perkin-Elmer-Cetus) as described previously. ${ }^{26}$ After a primary denaturing process for $5 \mathrm{~min}$ at $95^{\circ} \mathrm{C}$ to ensure complete denaturation of target DNA, the samples were subjected 35 times in succession to the following thermal cycle: denaturation for $1 \mathrm{~min}$ at $95^{\circ} \mathrm{C}$, annealing for $1 \mathrm{~min}$ at $48^{\circ} \mathrm{C}$ and polymerisation for $2 \mathrm{~min}$ at $72^{\circ} \mathrm{C}$. Thermal cycling was performed in a programmable heat block (Perkin-Elmer-Cetus). ${ }^{26}$

\section{Analysis of amplification products}

Amplified samples (50- $\mu$ l volumes) were subjected to electrophoresis through polycrylamide $(7 \cdot 5 \%)$ gel and visualised by staining with ethidium bromide. The nucleic acids were transferred from the polyacrylamide gel to Zeta Probe membranes (BioRad) by electroblotting. Prehybridisation was performed in $5 \times \operatorname{SSPE}\left(0.9 \mathrm{M} \mathrm{NaCl}, 50 \mathrm{mM} \mathrm{NaH} \mathrm{PO}_{4}\right.$ and $5 \mathrm{~mm}$ EDTA, pH 7.4), $5 \times$ DET (polyvinylpyrrolidone, Ficoll, bovine serum albumin, each at $0.1 \% \mathrm{w} / \mathrm{v}$ ) and sodium dodecyl sulphate $0.2 \% \mathrm{w} / \mathrm{v}$ for $2 \mathrm{~h}$ at $55^{\circ} \mathrm{C}$. Radiolabelled oligonucleotides, $10^{5} \mathrm{cpm} / \mathrm{ml}$, were then added and hybridisation was allowed to proceed for $20 \mathrm{~h}$ at $55^{\circ} \mathrm{C}$ in the same buffer. The membranes were then washed twice in $5 \times$ SSPE-sodium dodecyl sulphate $0.2 \% \mathrm{w} / \mathrm{v}$ at $30^{\circ} \mathrm{C}$ for $10 \mathrm{~min}$ each time and once for $10 \mathrm{~min}$ at $55^{\circ} \mathrm{C}$ in the same solution. The membranes were dried in air and autoradiographed at $-80^{\circ} \mathrm{C}^{26,27}$

\section{Results}

Sensitivity and specificity of primers for detection of $B$. burgdorferiflagellin gene

The primers were tested for PCR amplification of nucleic acids of B. burgdorferi, human lymphocytes 
and typical bacterial agents of meningitis. The amplified 290-bp fragment was visible in ethidium bromide-stained gels when DNA of any $B$. burgdorferi isolate was the target and the spirochaete suspension was diluted up to $10^{5}$-fold, equivalent to $c .10$ bacteria per sample (fig. 2). This calculation was based on a bacterial density of $10^{8}$ spirochaetes/ml of culture fluid, determined with a Petroff-Hauser counting chamber. A visible amplification product of $c .290 \mathrm{bp}$ hybridised with the oligonucleotide probe WK3. We could not amplify any DNA sequences from human lymphocytes. The hybridisation with probe WK3 was specific to DNA fragments of the expected size in positive samples. There was no evidence for nonspecific hybridisation of probe WK3 to human DNA. Nucleic acid sequences of bacteria other than B. burgdorferi were not amplified with the described oligonucleotides.

\section{Detection of B. burgdorferi DNA in clinical samples}

After PCR amplification, electrophoresis and hybridisation, the presence of the $B$. burgdorferi flagellin gene was demonstrated in culture samples of different B. burgdorferi strains and in CSF samples from both patients with clinically diagnosed Lyme borreliosis (fig. 3). All control CSF samples gave negative results both with ethidium bromide staining and with hybridisation.

\section{Discussion}

The cultivation of $B$. burgdorferi has been considered to be the reference method for demonstrating the

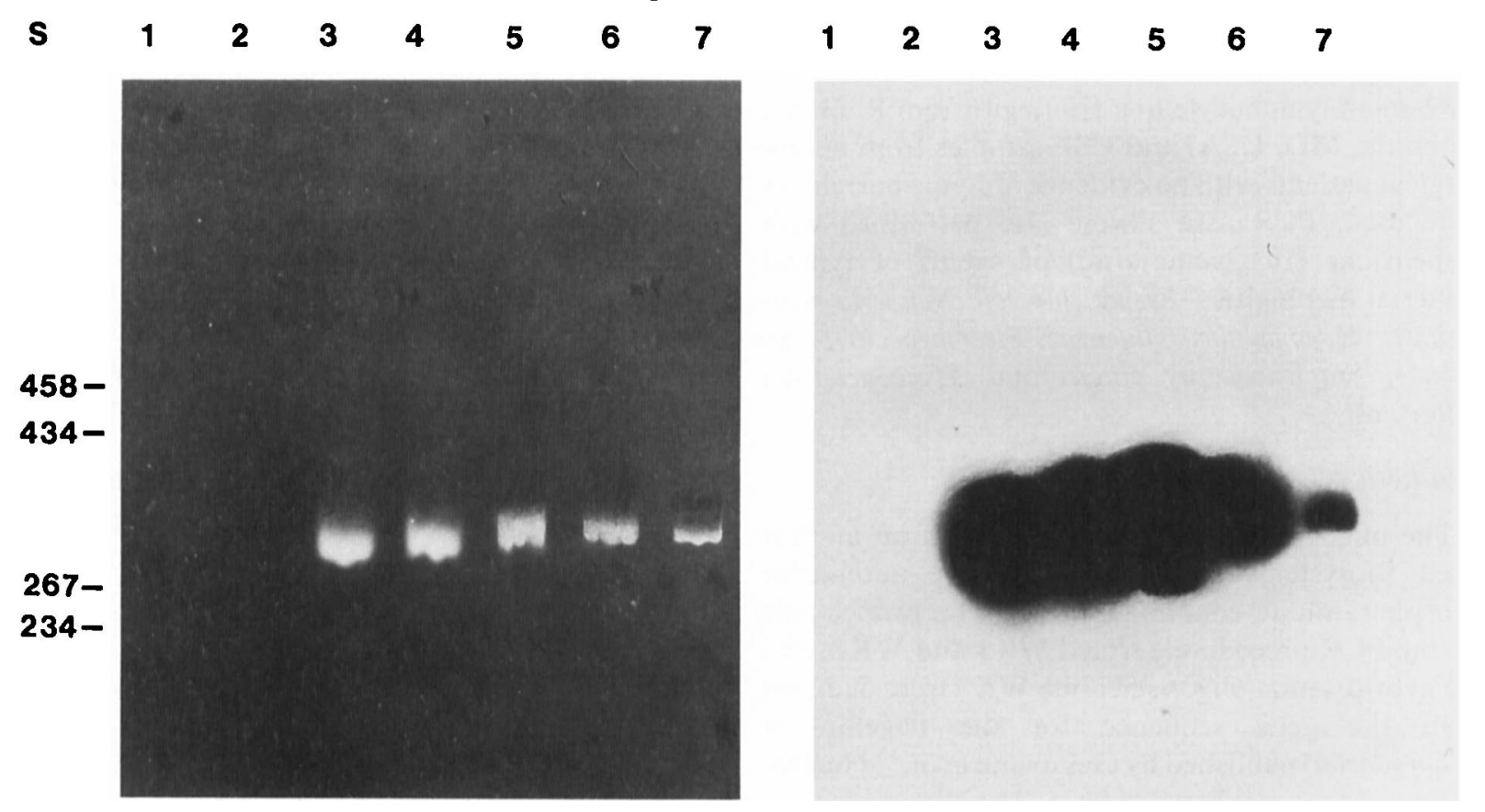

infectious agent of Lyme disease in clinical specimens from patients and in ticks. However, culture of this fastidious organism is difficult and requires incubation for about 6 weeks. ${ }^{17,19,20}$ We have established PCR for rapid and sensitive detection of $B$. burgdorferi in CSF. Because clinical samples contain only a few organisms, sensitivity is an obligate requirement for any PCR assay for the Lyme disease spirochaete. This system is practicable because we were able to detect a few $(\leq 10)$ bacteria in dilutions of liquid cultures. DNA was amplified from all $B$. burgdorferi isolates tested. By employing larger sample volumes, the sensitivity of PCR for clinical use might be increased.

The gene amplification technique offers advantages over culture. It is not necessary to have viable organisms in specimens. Thus, in our second patient with neuroborreliosis, the clinical diagnosis of Lyme disease could be confirmed only be gene amplification. Cultures remained negative and borrelia-specific antibodies were not detected. Cases with positive CSF cultures for $B$. burgdorferi but with negative serology in CSF and serum have been described. In the past, the diagnosis in such cases depended upon successful culture or subsequent seroconversion and was very time-consuming. PCR allows a rapid diagnosis, even in seronegative patients. ${ }^{10,16-18,20}$

Survival of $B$. burgdorferi in antibiotic-treated patients with Lyme disease of the central nervous system has been described. ${ }^{17} \mathrm{We}$ were able to detect borreliaspecific DNA in CSF from the first patient 2 weeks after beginning antimicrobial therapy; 4 weeks later, B. burgdorferi DNA was not detectable in CSF samples, in parellel with the clinical improvement seen. Thus PCR may prove to be a useful and sensitive method for monitoring therapy in patients with neuroborreliosis.

Fig. 2. Electrophoretic separation (a) and corresponding Southern blot hybridisation assay (b) of amplified $B$. burgdorferi flagellin gene sequences. Lanes 1 and 2: negative controls, no signal was detected when distilled water (1) or human lymphocyte DNA (2) was submitted to PCR; 3-7: amplified DNA from 10- $\mu$ l samples of $B$. burgdorferi strain B31 cultures, diluted $10^{1}-10^{5}$-fold respectively. 


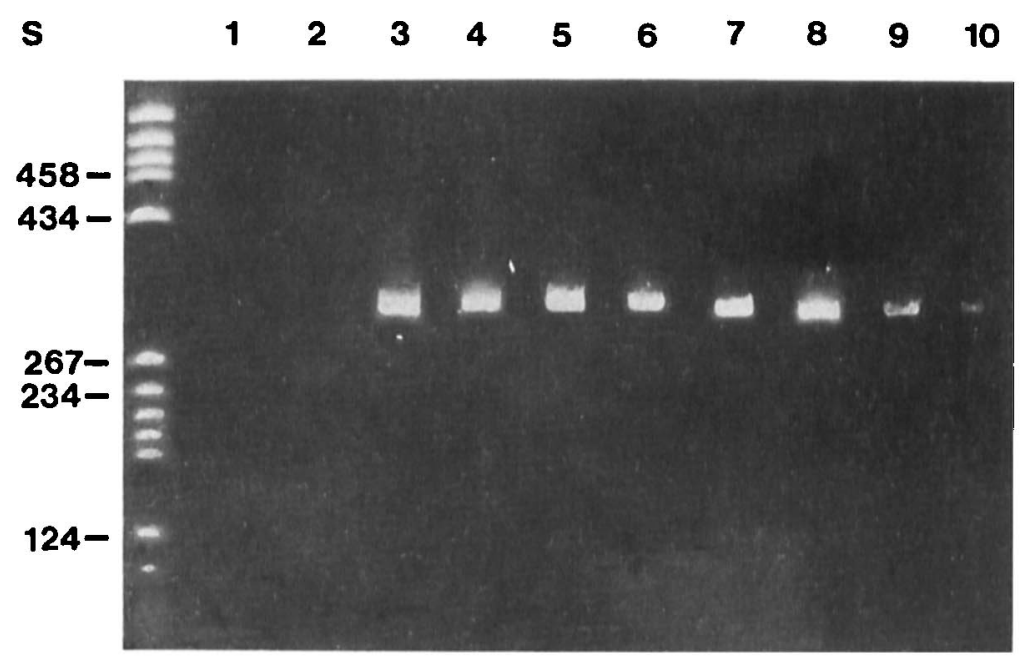

$\begin{array}{llllllllll}1 & 2 & 3 & 4 & 5 & 6 & 7 & 8 & 9 & 10\end{array}$

Fig. 3. Amplified flagellin gene sequences from culture dilutions $\left(10^{-3}\right)$ of different $B$. burgdorferi strains and from CSF. The electrophoretic profiles (a) and corresponding Southern blot patterns (b) are shown after hybridisation with the oligonucleotide probe WK3. Control preparation (left lane) for size in bp was pBR322 DNA, digested with HaeIII. Lane 1: distilled water; 2: human DNA from H9- cells (negative control); 3: B. burgdorferi strain B31 (ATCC 35210); 4: strain IRS (ATCC 35211); 5-8: clinical isolates 50, 387, N34 and PKO respectively; 9: CSF sample from patient $1 ; 10:$ CSF sample from patient 2 .

This test may also help detect $B$. burgdorferi in other specimens, e.g., synovial fluid from patients with Lyme arthritis, a manifestation of B. burgdorferi infection more frequently reported from the USA.
The cultivation of $B$. burgdorferi from synovial fluid appears to be even less successful than from CSF. ${ }^{28,20}$

We thank Carola Schlüter for preparing the photographs.

\section{References}

1. Anderson JF, Magnarelli LA, Burgdorfer W, Barbour AG. Spirochetes in Ixodes dammini and mammals from Connecticut. Am J Trop Med Hyg 1983; 32: 818-824.

2. Burgdorfer W, Barbour AG, Hayes SF, Benach JL, Grunwaldt E, Davis JP. Lyme disease - a tick-borne spirochetosis? Science $1982 ; 216 ; 1317-1319$.

3. Burgdorfer W. Discovery of the Lyme disease spirochete and its relation to tick vectors. Yale J Biol Med 1984; 57: 515520.

4. Preac-Mursic V, Wilske B, Schierz G, Suiss E, Gross B. Comparative antimicrobial activity of the new macrolides against Borrelia burgdorferi. Eur J Clin Microbiol Infect Dis 1989;8: 651-653.

5. Ackermann R, Hörstrup P, Schmidt R. Tick-borne meningopolyneuritis (Garin-Bujadoux, Bannwarth). Yale $J$ Biol Med 1984; 57: 485-490.

6. Bourke SJ. Lyme disease. Biomed Pharmacother 1989; 43: 397400.

7. Mertens HG, Martin R, Kohlhepp W. Clinical and neuroimmunological findings in chronic Borrelia burgdorferi radiculomyelitis (Lyme disease). $J$ Neuroimmunol 1988; 20: 309-314.

8. Pachner AR, Steere AC. Neurological findings of Lyme disease. Yale J Biol Med 1984; 57: 481-483.

9. Editorial. Diagnosis of Lyme disease. Lancet 1989; 2: 198-199.

10. Karlsson M, Möllegard I, Stiernstedt G, Wretlind B. Comparison of Western blot and enzyme linked immunosorbent assay for diagnosis of Lyme borreliosis. Eur J Clin Microbiol Infect Dis 1989; 8: 871-877.

11. Kohlhepp W, Kuhn W, Krüger H. Extrapyramidal features in central Lyme borreliosis. Eur Neurol 1989; 29: 150-155.

12. Baig S, Olsson T, Link H. Predominance of Borrelia burgdorferi specific B cells in cerebrospinal fluid in neuroborreliosis. Lancet 1989; 2: 71-74. 
13. Cutler SJ, Wright DJM. Comparison of immunofluorescence and enzyme linked immunosorbent assays for diagnosing Lyme disease. J Clin Pathol 1989; 42: 869-871.

14. Fawcett PT, O'Brien AE, Doughty RA. An adsorption procedure to increase the specitivity of enzyme-linked immunosorbent assays for Lyme disease without decreasing sensitivity. Arthritis Rheum 1989; 32 : 1041-1044.

15. Lawton NF, Bateman DE, Guy EC. Acute neuroborreliosis in a patient previously infected with Borrelia burgdorferi. Lancet $1989 ; 2: 390$.

16. Pfister H-W, Preac-Mursic V, Wilske B, Einhäupl K-M, Weinberger K. Latent Lyme neuroborreliosis: presence of Borrelia burgdorferi in the cerebrospinal fluid without concurrent inflammatory signs. Neurology 1989; 39: 11181120.

17. Preac-Mursic V, Weber K, Pfister HW et al. Survival of Borrelia burgdorferi in antibiotically treated patients with Lyme borreliosis. Infection 1989; 17: 355-359.

18. Karlsson M, Hovind-Hougen K, Svenungsson B, Stiernstedt G Cultivation and characterization of spirochetes from cerebrospinal fluid of patients with Lyme borreliosis. $J$ Clin Microbiol 1990; 28 : 473-479.

19. Steere AC, Grodzicki RL, Craft JE, Shrestha M, Kornblatt
AN, Malawista SE. Recovery of Lyme disease spirochetes from patients. Yale J Biol Med $1984 ; 57 ; 557-560$

20. Steere AC. Lyme disease. $N$ Engl J Med 1989; 321 : 586-596.

21. Aoki SK, Holland PV. Lyme disease-another transfusion risk? Transfusion $1989 ; 29$ : 646-650.

22. Dattwyler RJ, Luft BJ. Antibiotic treatment of Lyme borreliosis. Biomed Pharmacother $1989 ; 43: 421-426$.

23. Mullis KB, Faloona FA. Specific synthesis of DNA in vitro via a polymerase-catalyzed chain reaction. Methods Enzymol 1987; 155: 335-350.

24. Steere AC, Grodzicki RL, Kornblatt AN et al. The spirochetal etiology of Lyme disease. N Engl J Med 1983; 308: 733740.

25. Gassmann GS, Kramer M, Göbel UB, Wallich R. Nucleotide sequence of a gene encoding the Borrelia burgdorferi flagellin. Nucleic Acids Res 1989; 17: 3590.

26. Karch H, Meyer T. Single primer pair for amplifying segments of distinct Shiga-like-toxin genes by polymerase chain reaction. J Clin Microbiol 1989; 27: 2751-2757.

27. Maniatis T, Fritsch EF, Sambrook J. Molecular cloning: a laboratory manual. Cold Spring Harbor, NY, Cold Spring Harbor Laboratory. 1982.

28. Kahan A, Amor B, Menkes CJ. Lyme arthritis. Biomed Pharmacother 1989; 43: 401-403. 